\title{
Tumor-associated macrophage is correlated with survival and SOCS protein expression in canine mammary carcinoma ${ }^{1}$
}

\author{
Carlos H.C. Vieira-Filho ${ }^{2,3}$, Stella M. Barrouin-Melo ${ }^{2,3}$, Karine A. Damasceno ${ }^{4}$, \\ Márcio S.S. Araújo ${ }^{5}$, Natalie F. Borges ${ }^{6}$, Fabiana L. Silva ${ }^{7}$, Geovanni D. Cassali ${ }^{8}$ \\ and Alessandra Estrela-Lima ${ }^{2,3 *}$
}

\begin{abstract}
Vieira-Filho C.H.C., Barrouin-Melo S.M., Damasceno K.A., Araújo M.S.S., Borges N.F., Silva F.L., Cassali G.D. \& Estrela-Lima A. 2018. Tumor-associated macrophage is correlated with survival and SOCS expression in canine mammary carcinoma. Pesquisa Veterinária Brasileira 38(10):1972-1980. Escola de Medicina Veterinária e Zootecnia, Universidade Federal da Bahia, Av. Adhemar de Barros 500, Ondina, Salvador, BA 40170110, Brazil. E-mail: aestrela@ufba.br

The inflammatory infiltrate in the tumor microenvironment, particularly in mammary tumors, has aroused great interest in oncology, to play different roles in the progression or tumor regression dependent on the types and cell subsets involved. The present study aimed to evaluate (1) the occurrence and intensity of macrophage infiltration in the mammary carcinoma microenvironment, (2) the expression of SOCS1 and SOCS3 proteins in tumor associated macrophages, (3) any association between these parameters and tumor development, as well as survival rates in female dogs. Twenty-two female dogs diagnosed as carcinoma arising in a mixed tumor (CMT) by histopathology were divided into two groups following mastectomy: dogs without metastasis (CMT(-) $=11$ ) and those with metastasis (CMT $(+)=11)$. The following parameters were analyzed: tumor size, lymph node metastasis, clinical stage, histological grade, distribution and intensity of inflammatory infiltrate, tumor macrophage quantification by immunohistochemical analysis of SOCS1 and SOCS3 expression, and immunophenotyping of peripheral blood leukocytes by flow cytometry. Dogs with the higher proportions of macrophages in the inflammatory infiltrate ( $\geq 400 /$ tumor) also had higher survival rates in comparison with dogs with less macrophages. Immunostaining revealed higher proportions of SOCS3-positive macrophages in dogs without lymph node metastasis, while SOCS1-positive macrophages were predominant in dogs with metastasis $(\mathrm{p}<0.05)$. Multivariate analysis found associations between survival rate and clinical staging $(p=0.025)$, histological grade $(\mathrm{p}=0.007)$, and the expression of MHC-CI in circulating monocytes $(\mathrm{p}=0.018)$. Higher SOCS3 expression in activated macrophages within the inflammatory infiltrate were considered
\end{abstract}

\footnotetext{
${ }^{1}$ Received on November 23, 2017.

Accepted for publication on December 29, 2017.

2 Programa de Pós-Graduação Ciência Animal nos Trópicos, Escola de Medicina Veterinária e Zootecnia, Universidade Federal da Bahia (UFBA), Av. Adhemar de Barros 500, Salvador, BA 40170-110, Brazil. E-mails: chfilho@bol.com.br, barrouin@ufba.br; *Corresponding author: aestrela@ufba.br, alestrela@gmail.com

${ }^{3}$ Departamento de Anatomia, Patologia e Clínicas, Escola de Medicina Veterinária e Zootecnia, Universidade Federal da Bahia (UFBA), Av. Adhemar de Barros 500, Salvador, BA 40170-110.

${ }^{4}$ Laboratório de Patologia Experimental, Centro de Pesquisa Gonçalo Moniz (CPqGM), Fundação Osvaldo Cruz (Fiocruz), Rua Waldemar Falcão 121, Salvador, BA 40296-710. E-mail: karine.damasceno@bahia.fiocruz.br
}

\footnotetext{
${ }^{5}$ Laboratório de Biomarcadores de Diagnóstico e Monitoração, Centro de Pesquisas René Rachou (CPqRR), Fundação Oswaldo Cruz (Fiocruz), Av. Augusto de Lima 1715, Belo Horizonte, MG 30190-002, Brazil. E-mail: sobreira@cpqrr.fiocruz.br

${ }^{6}$ Centro de Ciências Ambientais, Agrárias e Biológicas, Universidade Federal do Recôncavo da Bahia (UFRB), Rua Rui Barbosa 710, Cruz da Almas, BA 44380-000, Brasil. E-mail: borgesnf@gmail.com

${ }^{7}$ Departamento de Ciências Agrárias e Ambientais, Universidade Estadual de Santa Cruz (UESC), Rodovia Jorge Amada Km 16, Distrito de Salobrinho, Ilhéus, BA 45662-900, Brazil. E-mail: fabiana.lessa@gmail.com

${ }^{8}$ Laboratório de Patologia Comparada, Departamento de Patologia Geral, Instituto de Ciências Biológicas, Universidade Federal de Minas Gerais (UFMG), Av. Presidente Antônio Carlos 6627, Belo Horizonte, MG 31270-901. E-mail: cassaliig@icb.ufmg.br
} 
indicative of an antitumor immune response, improved clinicopathological parameters and longer survival, whereas SOCS1-related activation was associated with tumor progression, metastasis development and reduced survival in female dogs with mammary carcinomas.

INDEX TERMS: Canine mammary carcinoma, tumor, dog, macrophages, cytokine, dogs, pathology.

\begin{abstract}
RESUMO.- [Correlação do infiltrado macrofágico com a sobrevida e a expressão da proteína SOCS no carcinoma mamário canino.] 0 infiltrado inflamatório no microambiente
\end{abstract} tumoral, particularmente nos tumores mamários, tem despertado grande interesse na oncologia, por desempenhar diferentes funções na progressão ou regressão tumoral, dependendo dos tipos e subtipos celulares envolvidos. 0 presente estudo teve como objetivo avaliar: (1) a ocorrência e a intensidade do infiltrado macrofágico no microambiente do carcinoma mamário; (2) a expressão das proteínas SOCS1 e SOCS3 nos macrófagos associados ao tumor; (3) qualquer associação relacionada ao prognóstico entre estes parâmetros e o desenvolvimento tumoral, assim como a taxa de sobrevida. Vinte e duas cadelas diagnosticadas com carcinoma em tumor misto (CTM) por exame histopatológico foram divididas em dois grupos após a mastectomia: cadelas sem metástase $($ CTM $(-)=11)$ e cadelas com metástase $(\mathrm{CTM}(+)=11)$. Foram analisados os seguintes parâmetros: tamanho do tumor, metástase para linfonodo, estadiamento clínico, grau histológico, distribuição e intensidade do infiltrado inflamatório, quantificação dos macrófagos tumorais por análise imuno-histoquímica da expressão de SOCS1 e SOCS3, e imunofenotipagem dos leucócitos (monócitos e linfócitos) do sangue periférico por citometria de fluxo. Cadelas que apresentavam maiores proporções de macrófagos no infiltrado inflamatório ( $\geq 400 /$ tumor) também tiveram maior taxa de sobrevida em comparação àquelas com menos macrófagos. A imunomarcação revelou maiores proporções de macrófagos SOCS3-positivos em cães sem metástase para linfonodo, enquanto que macrófagos SOCS1-positivos foram predominantes naqueles com metástase $(p<0,05)$. A análise multivariada identificou associações entre a taxa de sobrevida e o estadiamento clínico $(\mathrm{p}=0,025)$, grau histológico $(\mathrm{p}=0,007)$ e a expressão de MHC-CI em monócitos circulantes ( $\mathrm{p}=0,018)$. A maior expressão de SOCS3 nos macrófagos ativados foi considerada indicativa de uma resposta imune antitumoral, melhores parâmetros clínicos e maior taxa de sobrevida, ao passo que a ativação relacionada com SOCS1 foi associada à progressão tumoral, desenvolvimento de metástase e redução na taxa de sobrevida em cadelas com carcinoma mamário.

TERMOS DE INDEXAÇÃO: Carcinoma mamário canino, tumor, cadela, macrófagos, citocina, caninos, patologia.

\section{INTRODUCTION}

Macrophages are important innate immune cells that play essential roles in the primary response to pathogens, normal tissue homeostasis, the presentation of foreign and self-antigens following infection or injury, resolution of inflammation and wound healing. Like other immune effector cells, macrophages exhibit multiple subtypes and take on various phenotypes depending on conditions in the microenvironment (Mantovani 2007). Additionally, among inflammatory cells, these are the primary cell type involved in the response to neoplastic stimulation, as well as the second most common cell type found in the inflammatory infiltrate of mammary carcinomas in dogs, surpassed only by lymphocytes (Estrela-Lima et al. 2010).

Tumor-associated macrophages (TAMs) have been classified as analogous to Th1/Th2 cells in two distinct states of polarized activation: classically activated (M1) and alternatively activated (M2) macrophage subsets (Murray \& Wynn 2011). The M1 macrophages are considered pro-inflammatory, since they secrete high levels of proinflammatory cytokines (e.g., TNF- $\alpha$, IL-1, IL-6, IL-12 and IL-23) and have increased concentrations of superoxide anions, reactive oxygen and nitrogen species (Fairweather \& Cihakova 2009, Sindrilaru et al. 2011). Furthermore, M1 macrophages can express high levels of MHC class I and II antigens and secrete complement factors that facilitate complement-mediated phagocytosis (Mantovani et al. 2004). Alternatively activated M2 macrophages, considered anti-inflammatory, promote healing and tissue repair, and may stimulate tumor progression by the production of cell growth factors, anti-inflammatory cytokines and immunomodulators in Treg cells (Mantovani 2007).

Some authors have suggested that M1 macrophages, derived from pro-inflammatory activation, may be important to anti-tumor immunity and can be related to a better prognosis, while M2 macrophages are associated with a poorer prognosis, tumor progression and metastasis (Mantovani et al. 2002). The M2 cells function as promoters of neoplastic growth by producing growth factors related to angiogenesis and tissue remodeling (Mantovani et al. 2002, Martinez et al. 2009). In human breast carcinomas, the presence of pro-inflammatory TAMs in inflammatory infiltrate is related to a better response to chemotherapy, while reduced survival rates are related to macrophages activated by anti-inflammatory cytokines (Ono 2008, Heys et al. 2012, Hu et al. 2012). Other authors have attempted to determine whether the macrophage activation state inhibits the expression of some proteins (Italiani \& Boraschi 2014), among them SOCS (suppressor of cytokine signaling), regulators of negative feedback signaling of cytokines involved in the JAK-STAT pathway. The SOCS proteins 1 and 3 have been comprehensively studied due to their high action potential, as well as involvement in inflammation and tumor development (Starr \& Hilton 1998). The SOCS3 was found to be required for the classical macrophage activation, which is mediated by IL- 6 , while SOCS1, activated by IFN- $\gamma$, was shown to be needed for alternative activation in a study performed in women (Heys et al. 2012, Qin et al. 2012).

The clinicopathologic outcome of neoplasms associated with the balance between such ambivalent macrophages reflects the functional plasticity of these cells, which may have different functions in response to stimuli from the tumor microenvironment (Heys et al. 2012). The study of the inflammatory infiltrate in the tumor microenvironment, particularly in mammary tumors, has aroused great interest in human and veterinary oncology. It seems that the degree of tumor-associated inflammation and the predominant 
cell types and subtypes involved are associated with tumor progression or regression in response to treatment, in addition to influencing survival rate (Estrela-Lima et al. 2010, Heys et al. 2012, Kim et al. 2012, Saeki et al. 2012).

Accordingly, in light of the dearth of information pertaining to different profiles of macrophage activation in mammary carcinomas, the present study aimed to evaluate the density of TAMs in the tumor microenvironment, as well as the expression of SOCS 1 and 3 as markers related to activation status. Additionally, correlations between these parameters and the outcome of tumor progression, treatment response and survival were assessed as potential prognostic and predictive markers in canine mammary carcinoma.

\section{MATERIALS AND METHODS}

Ethics statement. All procedures performed in this study were conducted in compliance with the guidelines established by the Colégio Brasileiro de Experimentação Animal (Brazilian College of Animal Use in Experimentation, COBEA). The present study received approval from the Comissão de Ética no Uso de Animais (Review Board on the Use of Animals, CEUA) of the Universidade Federal da Bahia, Brazil (protocol no. 11/2013).

Animal groups. Twenty-two purebred or mixed-breed female dogs, aged 8-18 years, were included following routine examination at the Teaching Hospital of Veterinary Medicine of the Federal University of Bahia (UFBA). Sample selection was performed between March 2013 and February 2015.

All dogs underwent a comprehensive clinical examination, including detailed evaluation of physiological parameters, analysis of historical evolution and reproductive records along with hematological analysis. The dogs that had mammary neoplasms were physically evaluated to assess tumor location and features (size, presence of inflammatory reaction and/or ulceration), as well as evidences of regional lymph node metastasis. All dogs with a mammary tumor bigger than $3 \mathrm{~cm}$ in size were subjected to mastectomy, and tumor samples categorized by histopathological evaluation (Misdorp et al. 1999, Cassali et al. 2014). Finally, female dogs diagnosed with CTM were selected.

The CTM dogs were distributed into two groups based on histological analysis of the lymph nodes, as follows: i) no lymph node metastasis CMT(-) (n=11) or lymph node metastasis CMT(+) $(n=11)$. Exclusion criteria were the prior use of anti-neoplastic drugs, anti-inflammatory drugs or antibiotics within the 30 days prior to surgical excision, co-morbidity with infectious diseases or distant metastasis (Estrela-Lima et al. 2010).

Clinical evaluation and mastectomy. Following a thorough clinical examination, female dogs were categorized by a complete staging determined from information on the size tumor ( $\mathrm{T}$ ), involvement of regional lymph node $(\mathrm{N})$ and the presence or absence of distant metastases (M) (TNM system) (Owen 1980). Macroscopic evaluation of the inguinal and axillary lymph nodes was performed by palpation. Neoplastic involvement was confirmed by histopathological examination of the lymph nodes following mastectomy. Radiological examinations of the chest in three planes, laterolateral right and left (LL) and ventrodorsal (VD), were performed to investigate lung metastasis.

All dogs were subjected to unilateral radical mastectomy, including the removal of the inguinal lymph nodes. Dogs were fitted with a compression bandage and monitored for 48 hours post-surgery.

Histological classification and grading. Fragments of the affected mammary gland, including skin and subcutaneous tissue surrounding the regional lymph nodes, were fixed in phosphate-buffered 10\% neutral formalin and embedded in paraffin. Histological sections (4- $\mu$ m thick) were stained by hematoxylin-eosin (HE) (Luna 1968). Duplicate slides were prepared and analyzed by two veterinary pathologists. All tumor samples were identified according to the histological classification established by the World Health Organization (WHO) (Misdorp et al. 1999) and the Consensus for the Diagnosis, Prognosis and Treatment of Canine Mammary Tumors (Cassali et al. 2014). The Nottingham histological grading system was used, including tubular differentiation percentage, assessment of nuclear pleomorphism and mitotic index (Elston \& Ellis 1993, Cassali et al. 2014).

Morphological and morphometric analysis of inflammatory infiltrate. The inflammatory response corresponding to each tumor sample was characterized according to intensity (discrete, moderate or intense) and distribution (focal, multifocal and diffuse). Under morphometric analysis, eight "hot spot" histological fields were selected for quantification (i.e., the fields with the most representative inflammatory responses observed in each case).

Morphometric analysis was then performed in these eight identified and marked fields, with images captured on a digital camera (Zeiss Axiocam/CC5) adapted to a microscope (Carl Zeiss Scope.A1) using Zeiss Zen 2012 Software (Blue Edition-Service Pack 1$)^{\circledR}$ and Corel DRAW ${ }^{\circledR}$ version X7 software for image analysis. Lymphocytes, macrophages, plasma cells, neutrophils and eosinophils were identified according to morphological characteristics and then quantified (Estrela-Lima et al. 2010).

Cell counts were obtained by totaling the eight fields laterolateral right and left analyzed and mean values were used to determine intensity. The intensity of inflammatory infiltrate was classified as follows: i) discrete, less than 500 inflammatory cells; ii) moderate, when inflammatory cells totaled 500-1,000; and iii) severe, when more than 1,000 inflammatory cells were identified. The intensity of tumor-associated macrophage (TAM) infiltration was determined as i) discrete to moderate (mean $<400)$, or ii) intense (mean $\geq 400$ ) (Estrela-Lima et al. 2010).

Immunohistochemical analysis. The immunohistochemical analysis of CD68 (mouse anti-human; Serotec - MCA5709, 1:60, Oxford, UK), SOCS1 (rabbit polyclonal IgG; Santa Cruz - SC-9021, 1:60, USA) and SOCS3 (rabbit polyclonal IgG; Santa Cruz - SC-9023, $1: 80$, USA) antibodies (macrophages and expression of SOCS proteins, suggesting their activation subtypes, respectively) was performed using 4- $\mu \mathrm{m}$ sections of each sample collected on gelatinized slides. All slides were deparaffinized, then rehydrated in a series of progressively diluted alcohol solutions and subjected to antigen retrieval in pH 6.0 citrate buffer (Target Retrieval Solution) (SOCS 1 and 3$)$ in a water bath $\left(95^{\circ} \mathrm{C}\right.$ for 20 minutes, with the exception of slides used for the detection of CD68. For enzyme treatment, proteinase $\mathrm{K}$ was incubated in a moist chamber for five minutes at room temperature. Subsequently, all slides were incubated in 3\% hydrogen peroxide in methanol to block the activity of endogenous peroxidase for 15 minutes. After cooling, slides were covered with blocking serum (Lab Vision ${ }^{\mathrm{TM}}$ Ultra V Block - Thermo Scientific) for 15 minutes. Histological sections were incubated with primary antibody for $1 \mathrm{~h}$ at $25^{\circ} \mathrm{C}$ and then polymerized (ADVANCE-HRP ready-to-use DakoCytomation). Finally, sections were exposed to chromogen 3,3-diaminobenzidine and counterstained with Mayer's hematoxylin. Negative controls were obtained by replacing the primary antibody with PBS and normal serum.

Immunophenotyping of circulating monocytes by flow cytometry. To evaluate cellular immune response, $4 \mathrm{~mL}$ of blood from all dogs were collected (30 minutes before performing mastectomy). Peripheral 
blood was collected into sterile $5 \mathrm{~mL}$ disposable syringes via jugular venipuncture, then transferred into sterile EDTA-containing tubes kept at room temperature. Hematological and immunophenotypical parameters were evaluated by an automatic blood cell analyzer (ADVIA $60^{\circledR}$, Bayer HealthCare, Tarrytown, USA) and a flow cytometer (FACScalibur, Becton Dickinson, San Jose, USA).

Monoclonal antibodies anti-CD14 Cy5, anti-MHCI FITC and anti-MHCII RPE (Serotec Ltd, Oxford, England) were diluted in PBS-W (phosphate buffered saline-PBS $=0.15 \mathrm{M}, 8 \mathrm{~g} / \mathrm{L} \mathrm{NaCl}, 2 \mathrm{~g} / \mathrm{L} \mathrm{KCl}$, $2 \mathrm{~g} / \mathrm{L} \mathrm{KH}_{2} \mathrm{PO}_{4}$ and $1.15 \mathrm{~g} / \mathrm{L} \mathrm{Na}_{2} \mathrm{HPO}_{4}, \mathrm{pH} 7.2$ with $0.5 \%$ bovine serum albumin (BSA), and $0.1 \%$ sodium azide) at a previously established dilution (Estrela-Lima et al. 2010).

Whole blood samples containing EDTA $(40 \mu \mathrm{L})$ were individually transferred into conical polystyrene tubes measuring $12 \times 75 \mathrm{~mm}$ (FALCON $^{\circledR}$; Becton Dickinson) containing $1 \mu \mathrm{L}$ of anti-MHCI (FITC) $+2 \mu \mathrm{L}$ anti-MHCII (R-PE) $+1 \mu \mathrm{L}$ anti-CD14 (Cy5). Each sample was thoroughly homogenized and incubated at room temperature for 30 minutes, protected from light. Next, cells were lysed by adding $3 \mathrm{~mL}$ of lysing solution (FACS LYSING SOLUTION; Becton Dickinson) under vortexing. The cell suspension was allowed to stand for 10 minutes at room temperature, protected from light, and then centrifuged at $400 \times g$ for seven minutes at room temperature. After centrifugation, the supernatant was discarded by decanting the tube, and the cell pellet was then homogenized by vortexing at low speed. Next, $3 \mathrm{~mL}$ of PBS-W was added, and the cellular suspension was again centrifuged at $400 \mathrm{xg}$ for seven minutes at room temperature; the supernatant was again discarded, and the pellet was resuspended and homogenized thoroughly; this final wash was then repeated once again. Cells were fixed with $100 \mu \mathrm{l}$ of MaxFacsFix (MFF) fixative solution $(10.0 \mathrm{~g} / \mathrm{L}$ paraformaldehyde, $10.2 \mathrm{~g} / \mathrm{L}$ sodium cacodylate and $6.65 \mathrm{~g} / \mathrm{L}$ sodium chloride, $\mathrm{pH} 7.2$ ), then subjected to flow cytometry analysis, which evaluated 10,000 events. Same-species, same-isotype antibodies were similarly obtained (Serotec - Oxford, England) and used as negative controls.

Cells were analyzed by a FACScalibur cytometer (Becton Dickinson) coupled to a computer system running BD CellQuest software (CELL Quest ${ }^{\circledR}$ ). Phenotypic characterization by flow cytometry included the simplified analysis of three cell parameters: size, as determined by laser diffraction; granularity "Forward scatter" (FSC), i.e. granularity or internal complexity, as determined by lateral refraction and reflection of the laser beam; "Side Scatter" (SSC), and the relative intensity of each fluorescence signal.

Data collection began with the cytometric identification of the cell population of interest (R1) after gain adjustment size (FSC) and granularity (SSC) and/or fluorescence (FL1, FL2 and FL3). After selecting the region of interest (R1), the analysis of phenotypic aspects was performed using two different approaches: i) by considering the percentage of positive cells expressed graphically in terms of timely dispersion of fluorescence, corresponding to the positive population for the relevant marker; and ii) by evaluating mean fluorescence intensity (MFI), determined as the density of expression of a particular phenotypic marker displayed by logarithmic histogram. The first approach was used to quantify cell phenotypes presenting bimodal distribution, i.e., the cell phenotypes that are characterized by positive and negative populations with respect to a given phenotypic marker. The second approach used a semi-quantitative analysis of phenotypic marker expression with univariate distribution - i.e., the total cell population of interest constitutively expressed by a given phenotypic marker. In these situations, changes in the expression density can occur, promoting the shift of the cell population along the fluorescence intensity axis. For each sample analyzed, a control reaction was performed to assess the quality of the cellular profile and to detect possible nonspecific fluorescence.

Survival rates. The follow-up for determining overall survival and clinical outcomes was performed by clinical examination and laboratory testing (CBC and serum biochemistry - urea, creatinine, ALT and FA) every 30 days for at least nine months after surgery. Radiological examinations were carried out every 90 days. Overall survival time was defined as the number of days between the date of surgical excision of the primary tumor and death. All dogs that died were necropsied to determine cause of death and to detect metastasis.

Statistical analysis. Data were submitted to the Kolmogorov-Smirnov test to evaluate distribution normality. For parametric and non-parametric data, Student's t-test/Mann-Whitney U test or ANOVA/Kruskal-Wallis one-way analysis of variance were used, respectively. Correlations were investigated using Pearson's or Spearman's tests. Survival curves were estimated using the Kaplan-Meier method and compared by log-rank testing (Mantel-Cox) or Cox univariate and multivariate analysis by correlating the intensity of macrophage infiltration with clinical and pathological responses.

Data were grouped according to: histological diagnosis (CMT); metastasis in lymph nodes (Y or N); clinical stage (II, III, IV or V); histologic grading (I, II or III); inflammatory distribution (focal, multifocal or diffuse), inflammatory intensity (discrete, moderate or intense); TAM infiltration intensity $(<400$ or $\geq 400)$; percentage of SOCS protein expression by macrophages $(\geq 50 \%=$ positive for SOCS1 or SOCS3); and survival rate (low: $\leq 6$ months, or high: $>6$ months). In all cases, $p<0.05$ was considered statistically significant. Analyses were performed using Prism 5.0 software (GraphPad, San Diego, USA) and SPSS v. 17 (SPSS Inc., Chicago, USA).

\section{RESULTS \\ Clinicopathological evaluation}

Among the studied dogs $(n=22)$, all with mammary tumors, poodles was the most frequent breed (10/22, 45.45\%), followed by mongrel dogs $(7 / 22,31.80 \%)$, with a mean age of 12 years (age range of 8-15 years). The inguinal mammary glands $(8 / 22$, $36.36 \%$ ) were the sites most affected by tumors, regardless of side, with most tumors measuring $>5 \mathrm{~cm}(17,77.27 \%)$, 8 CMT(-)/9 CMT(+). Clinical stage III was predominant $(14 / 22,63.6 \%) 7$ CMT(-)/7 CMT(+), as well as histological grade II $(21 / 22,95.46 \%)$. None of the dogs presented with clinical evidences of metastasis; however, 11 (50\%) had metastases in the regional lymph node. Multicentric tumors were observed in $72.72 \%(16 / 22)$ of the dogs, exhibiting variable histological types.

\section{Morphologic, morphometric and immunohistochemical analysis of tumor-associated inflammatory infiltrate}

Morphological evaluation of the samples obtained by excisional biopsy revealed that tumor-associated inflammatory infiltrate exhibited moderately intense infiltration with predominantly mononuclear cells in multifocal distribution in all dog groups (Fig.1). Lymphocytes were the predominant cell population in all groups. Macrophages were more frequently found in the group of dogs without metastasis in comparison to the group that presented metastasis (Fig.2). Quantitative analysis performed on HE-stained slides confirmed cell morphology and immunostaining with the CD68 antibody. TAM $\geq 400$ was significantly associated with a high histological grade $(p=0.029)$ (Table 1). Histological sections immunostained with 


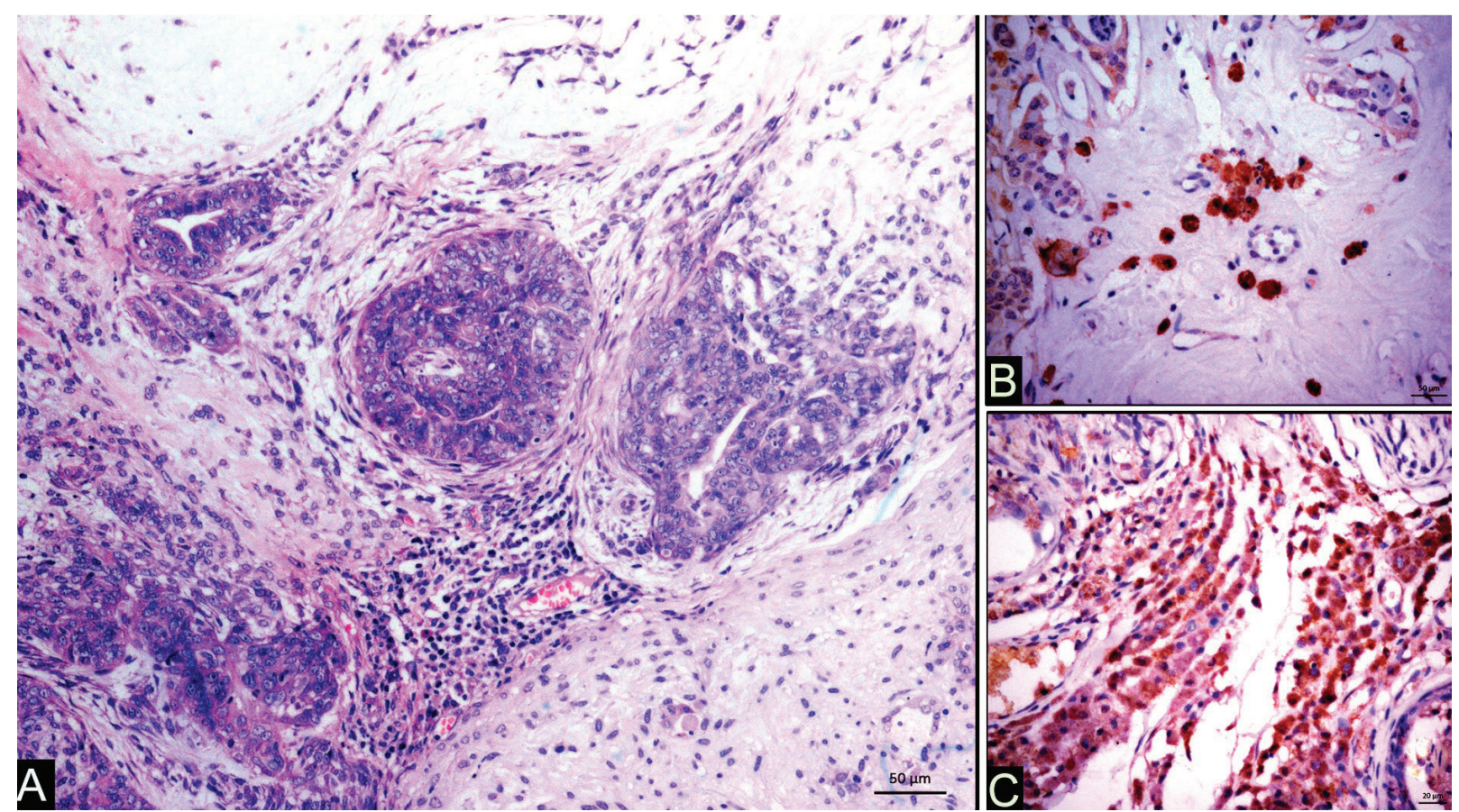

Fig.1. Histological diagnosis of canine mammary carcinoma and immunohistochemical staining for SOCS1 and SOCS3. (A) Carcinoma arising in a mixed tumor (CMT) associated with focal inflammatory infiltrate. HE, obj.40x. (B) Immunostained macrophages with cytoplasmic staining for SOCS1. (C) Immunostained macrophages with cytoplasmic staining for SOCS3.

CMT (-)

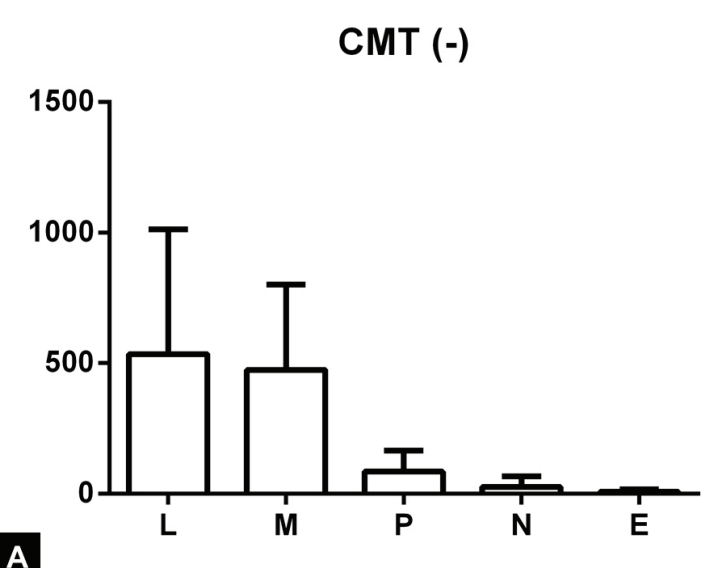

A

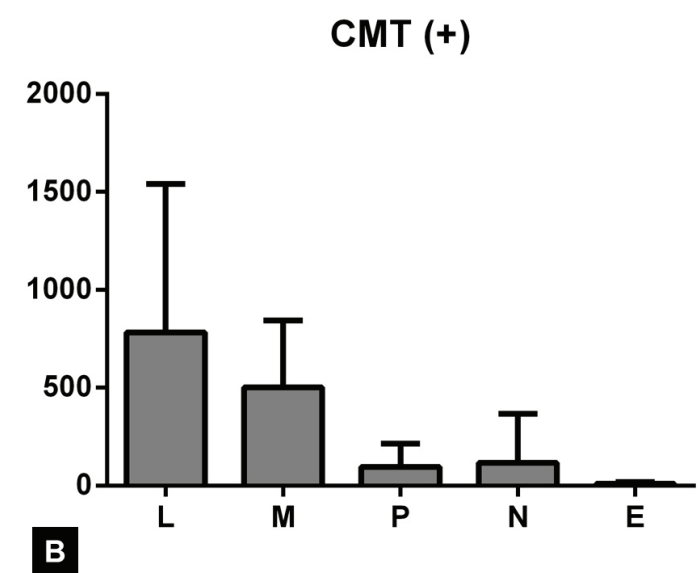

Fig.2. Composition of inflammatory infiltrate in carcinoma arising in a mixed tumor (CMT). Subcategorized according to (A) the absence (-) or

(B) presence ( + ) of lymph node metastasis. Inflammatory cells were characterized by image analysis. $\mathrm{L}=$ lymphocytes, $\mathrm{M}=\mathrm{macrophages,}$

$\mathrm{P}=$ plasma cells, $\mathrm{N}=$ neutrophils, $\mathrm{E}=$ eosinophils.

anti-SOCS1 and anti-SOCS3 antibodies revealed predominant expression of SOCS1 ( $\mathrm{p}=0.0097$ ) in TAMs from dogs with metastasized lymph nodes, while SOCS3 expression was predominant in the TAMs of dogs without metastasis of the lymph nodes ( $\mathrm{p}=0.014$ ) (Fig.3).

\section{Immunophenotyping of circulating monocytes by flow cytometry}

Immunophenotyping of peripheral blood by flow cytometry showed no significant differences with respect to the expression of MHC-CI and MHC-CII molecules, or CD14+ monocytes, among the four groups of studied dogs (Fig.4).

\section{Clinicopathological outcome and survival rate}

No significant differences were seen in clinical examinations and blood counts performed preoperatively, regardless of the presence or absence of lymph node metastasis. During follow-up, 15 of the 22 dogs died. Twelve of these 15 dogs were necropsied, and metastases were identified in the skin, liver, kidneys and lungs, in addition to paraneoplastic syndromes. Hypovolemic shock was the most frequent cause of death, particularly in the dogs with indicators for chemotherapy treatment (high histological grade and metastasis). The minimum survival period after surgery was 60 days, while the longest period was 695 days-within the limits of the study follow-up timeframe (Fig.5). 

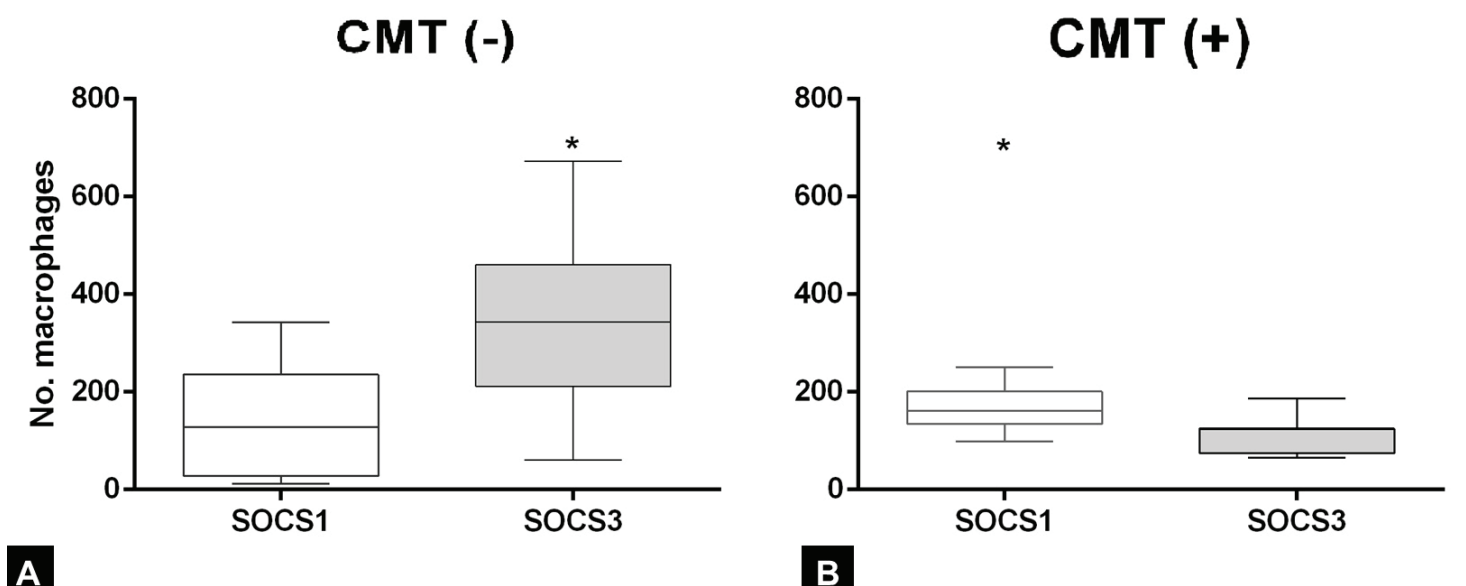

Fig.3. SOCS1 and SOCS3 protein expression in macrophage infiltrate in excisional biopsies of dogs with carcinoma arising in a mixed tumor (CMT). (A) The group of dogs without metastasis presented the largest number of TAMs positive for SOCS3; p=0.014. (B) The group of dogs with metastasis presented the largest number of TAMs positive for SOCS1; $p=0.0097$.

Table 1. Associations between clinical and pathological parameters and tumor-associated macrophage density $(<400$ or $\geq 400)$

\begin{tabular}{|c|c|c|c|c|}
\hline \multirow{2}{*}{\multicolumn{2}{|c|}{ Parameters }} & \multicolumn{2}{|c|}{ Macrophage density } & \multirow{3}{*}{$\frac{p \text {-value }}{0.65}$} \\
\hline & & \multirow{2}{*}{$\begin{array}{c}<400 \\
5(22.73 \%)\end{array}$} & \multirow{2}{*}{$\begin{array}{c}\geq 400 \\
6(27.27 \%)\end{array}$} & \\
\hline Condition & Alive & & & \\
\hline & Deceased & $5(22.73 \%)$ & $6(27.27 \%)$ & \\
\hline \multirow[t]{2}{*}{ Survival } & $<180$ days & $1(4.55 \%)$ & $4(18.18 \%)$ & 0.097 \\
\hline & $>180$ days & $9(40.91 \%)$ & $8(36.36 \%)$ & \\
\hline \multirow[t]{2}{*}{ Metastasis } & No & $5(22.73 \%)$ & $5(22.73 \%)$ & 0.696 \\
\hline & Yes & $5(22.73 \%)$ & 7 (31.1\%) & \\
\hline \multirow{2}{*}{$\begin{array}{l}\text { Histologic } \\
\text { grade }\end{array}$} & 1 & $4(18.18 \%)$ & $0(0.00 \%)$ & $0.029 *$ \\
\hline & 2 & $6(27.27 \%)$ & $12(54.55 \%)^{*}$ & \\
\hline \multirow[t]{2}{*}{ Size } & $3-5 \mathrm{~cm}$ & $4(18.18 \%)$ & $1(4.55 \%)$ & 0.105 \\
\hline & $>5 \mathrm{~cm}$ & $6(27.27 \%)$ & $11(50.00 \%)$ & \\
\hline \multirow{2}{*}{$\begin{array}{l}\text { Inflammatory } \\
\text { distribution }\end{array}$} & Peri & $4(18.18 \%)$ & $1(4.55 \%)$ & 0.105 \\
\hline & Intra & $6(27.27 \%)$ & $11(55.00 \%)$ & \\
\hline \multirow{3}{*}{$\begin{array}{l}\text { Inflammatory } \\
\text { intensity }\end{array}$} & Discreet & $1(4.55 \%)$ & $0(0.00 \%)$ & 0.467 \\
\hline & Moderate & $4(18.18 \%)$ & $4(18.18 \%)$ & \\
\hline & Intense & $5(22.73 \%)$ & $8(36.36 \%)$ & \\
\hline
\end{tabular}

*Significant difference, i.e. $p<0.05$. Fisher's exact test.

A comparison of survival curves stratified according to TAM level $(<400$ or $\geq 400)$ revealed that the dogs with $\mathrm{TAM} \geq 400$ (average survival=364 days) presented higher rates of survival, but without statistical significance (Fig.5).

\section{Univariate and multivariate analyses}

Univariate analysis of clinicopathological parameters correlated with higher density TAM $(\geq 400)$ revealed associations with clinical staging ( $\mathrm{p}=0.006)$, histological grading $(\mathrm{p}=0.015)$, tumor size $(\mathrm{p}=0.011)$ and the expression of MHCI molecules in circulating monocytes $(\mathrm{p}=0.001)$. Similar results were observed under multivariate analysis, in which a significant relationship was observed between TAM and clinical staging $(p=0.025)$, grading $(p=0.007)$, survival $(p=0.045)$ and the expression of MHCI molecules in circulating monocytes $(\mathrm{p}=0.018)$ (Table 2).
Table 2. Univariate and multivariate analysis of clinicopathological parameters associated with high tumor-associated macrophage density $(\geq 400)$

\begin{tabular}{lcc}
\hline \multirow{2}{*}{\multicolumn{1}{c}{ Parameters }} & \multicolumn{2}{c}{ Analysis type } \\
\cline { 2 - 3 } & Univariate & Multivariate \\
\hline Clinical stage & $0.006^{*}$ & $0.025^{*}$ \\
Histologic grade & $0.015^{*}$ & $0.007^{*}$ \\
Size & $0.011^{*}$ & 0.078 \\
Lymph node metastasis & 0.696 & 0.572 \\
Survival & 0.084 & $0.045^{*}$ \\
State of activation of TAM & 0.696 & 0.721 \\
IMF CD14+MHC II $^{+}$ & 0.335 & 0.944 \\
IMF CD14+MHC I+ & $0.001^{*}$ & $0.018^{*}$ \\
Inflammatory distribution & 0.072 & 0.078 \\
Inflammatory intensity & 0.303 & 0.140
\end{tabular}

*Selected for univariate and multivariate analysis. For univariate analysis, was used Spearman's correlation between variables. For multivariate analysis, was used logistic regression. Significant differences were considered when $\mathrm{p}<0.05$.

\section{DISCUSSION}

The roles played by TAMs in canine mammary carcinomas are not yet fully understood. As such, correlations between the predominant immunophenotypical features of the macrophage infiltrates and classic prognostic factors may offer some insight into associations between the host immune response and disease progression.

As in other studies conducted by our group, the results detailed herein do not present evidence regarding a particular breed's predisposition to mammary tumors, yet a higher frequency was again found in poodles and mongrels (Estrela-Lima et al. 2010, Toríbio et al. 2012). It is important to note that these higher frequencies might very likely be a reflection of breed preferences by owners, as observed since the beginning of the last decade (i.e. from 2000 on). At the time of diagnosis, the dogs' ages ranged from six to 14 years, with a median of 10 years, which is consistent with the age of risk reported by other studies (Lim et al. 2015). 
MFI CD14 MHC I
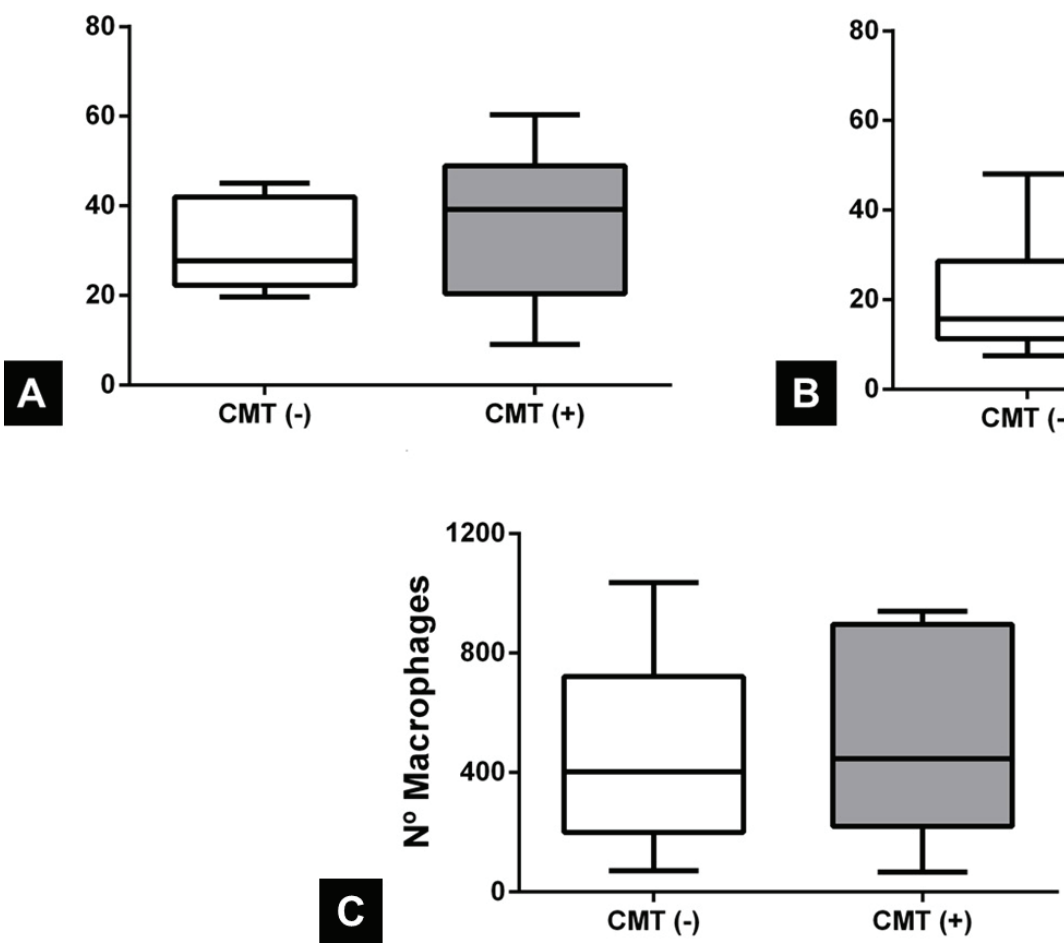

MFI CD14 MHC II

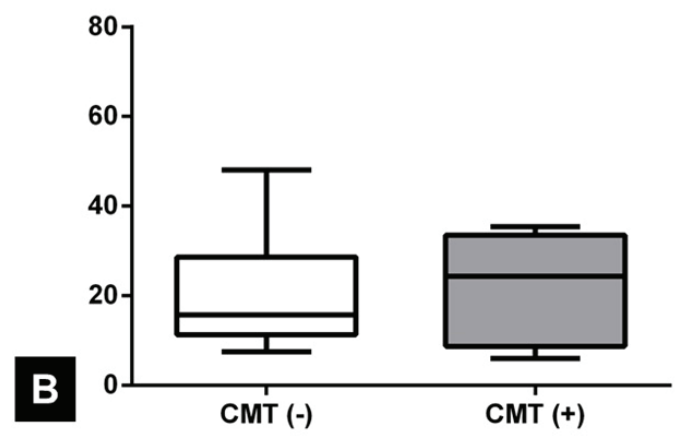

Fig.4. Expression of (A) MHC-CI and (B) MHC-CII molecules in canine circulating monocytes and macrophages, and TAM density in mixed tumors. MHC-CI and MHC-CII expression in CD14+ monocytes among the studied dog groups, segregated by the presence or absence of metastasis in lymph nodes. Monocyte populations were identified by flow. Data are expressed as the percentage of positive cells within the captured monocyte population. (C) Density of macrophage infiltration among the experimental groups. *Significant differences, i.e. p $<0.05$.

A

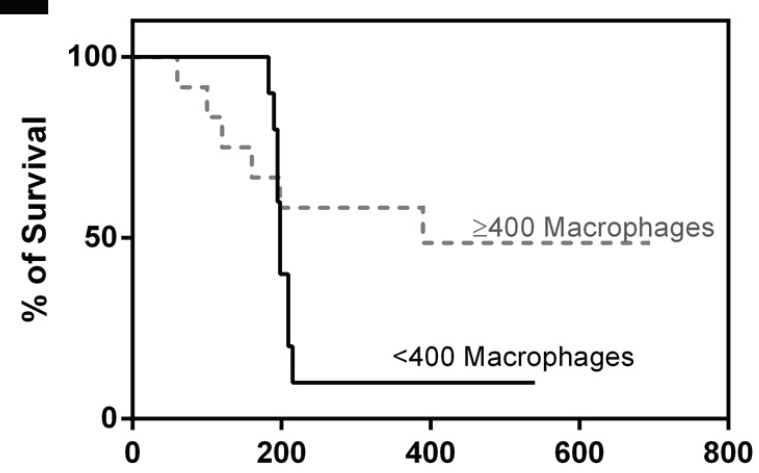

B

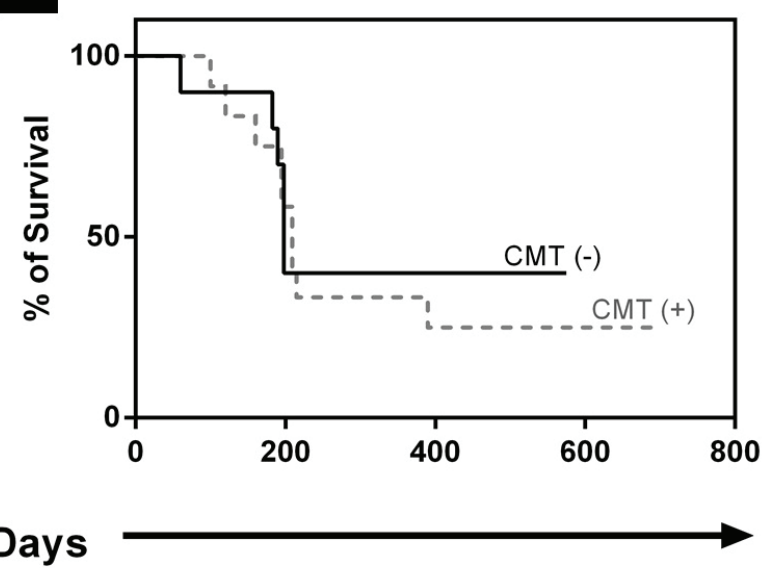

Fig.5. (A) Survival curves of dogs based on macrophage density $<400$ (TAM $<400$ ) or $\geq 400$ (TAM $\geq 400$ ) and subcategorization of studied groups according to the absence (-) or presence $(+)$ of lymph node metastasis. (B) Survival rates of dogs with carcinoma arising in a mixed tumor (CMT). Dogs were subjected to quarterly monitoring after surgery, and survival rate (\%) is expressed in days. Survival curves were generated using the Kaplan-Meier method, followed by the log-rank test. *Significant differences, i.e. $p<0.05$.

Morphological analysis of the tumor-associated inflammatory infiltrates in the present study indicated that lymphocytes were the most frequent cell type observed among immune cells, followed by macrophages. These findings are congruent with other reports in the human (Heys et al. 2012) and veterinary literature (Estrela-Lima et al. 2010).
A high density of TAM $(\geq 400)$ was significantly associated with high histologic grades in the dogs of this investigation. Similarly, Heys et al. (2012), in a study of breast carcinoma in women, described a higher density of TAM in tumors with higher histological grades and tumors that responded poorly to chemotherapy. However, differently than the findings of 
study with women, the dogs presenting higher density of TAM also had the higher survival rates, even though they also had higher histologic grades.

The expression of SOCS proteins, specifically SOCS1 and SOCS3, has been used to determine TAM activation status in studies involving women and rodents (Heys et al. 2012). However, it has been suggested that M1 and M2 may present a combination of multiple markers as SOCS, and other proteins may be highly expressed in either form, with differing patterns of expression seen in other species (Sica et al. 2008, Murray et al. 2014). In the present study, the expression of SOCS1 and SOCS3 proteins in anti- (M2) and pro-inflammatory (M1) macrophages, respectively, was found to be associated with breast carcinoma, which is consistent with a previous study involving women who had this same tumor type (Heys et al. 2012). Moreover, in humans, the predominance of SOCS-1 expression in the macrophage infiltrate was related to a higher histologic gradation, and a poorer prognostic (Heys et al. 2012). Differently, we found that the predominance of pro-inflammatory macrophage infiltrates (SOCS3), even in the dogs with higher density of TAM, suggested a better prognostic and therefore could be indicative for chemotherapy treatment, since the survival rates in this group was higher and the frequency of metastases was lower.

Chemical short-range signaling by M2 macrophages has a role in the development of metastasis, since it arises from the release of epidermal growth factor (EGF) and in response to colony stimulating factor-1 (CSF-1) (Qian et al. 2009, Rohan et al. 2014). The resultant potential increase in the malignancy of tumor cells occurs as a consequence of stromal remodeling (Guiet et al. 2011) following the release of metalloproteinases, collagenase, elastase and lipases (Mantovani 2007), as well as of production of cytokines and chemokines (CCL2, CCL3, VEGF) (Król et al. 2012).

The results observed herein corroborate reports in the literature indicating that M2 TAMs are associated with a poor prognosis of cancer. Indeed, the literature attributes to M2 the promotion of tumor growth, progression and metastasis by way of the production and release of growth factors (NF- $\kappa \beta$ ), immunomodulatory cytokines (IL-10, TGF- $\beta$ ), the stimulation of angiogenesis, remodeling of tumor stroma (matrix metalloproteinases) and inhibition of the anti-tumoral immune response (Mantovani et al. 2002, Mantovani 2007, 2014, Hu et al. 2012).

Most tissue mature macrophages arise in the tissues during embryonic development, i.e. the origin of these cells is not from the pool of circulating monocytes, which are rather directed to capture antigens circulating in the lymph nodes. Thus, in the context of inflammatory or neoplastic processes, tissue macrophages may maintain an undifferentiated state or mature into activated macrophages (Epelman et al. 2014). Neoplastic cells recruit TAMs by releasing chemoattractants (CSF-1 or M-CSF) and chemokines (chemokine ligand-2 and MCP-1) (Pollard 2008, Król et al. 2012). In the present study, the molecular expression of MHC-CII found in the circulating monocytes followed the same patterns of density distribution found in TAMs among the different study groups. This finding may be attributed to the release of MCP- 1 in the tumor microenvironment by tumor cells recruiting monocytes from peripheral blood in dogs with CMTs. However, complex interactions between TAMs and other inflammatory cells in the microenvironment, particularly $\mathrm{CD}^{+}{ }^{+} \mathrm{T}$ lymphocytes, can determine the state of macrophage activation thus the role of TAMs as potent effectors against cancer, or as stimulators of tumor growth (Qian et al. 2009). In fact, a previous report indicated that the production and release of antibodies against the tumor extracellular matrix components might somehow orchestrate the recruitment of circulating monocytes and influence the anti-inflammatory function of TAMs (Mantovani 2011).

The trend of increased survival in the group with a higher TAM density found here stands in contrast to results presented by Heys et al. (2012), which correlated a longer survival with lower TAM density. However these authors' study utilized incisional biopsy of breast cancer in women that were previously subjected to chemotherapy, and this represent the routinely adopted procedures, considering human patients and their natural characteristics. In veterinary medicine, the current procedure for dogs diagnosed with mammary tumor is the unilateral radical mastectomy, which allows the collection of excisional biopsy samples. Additionally the dogs of the present study were not treated with any drug before the surgery. Therefore, the results we obtained in dogs can be attributed to the natural development of the neoplasm, were more comprehensible since we used histopathology in excisional biopsy samples and were not influenced by any pharmacological intervention.

\section{CONCLUSION}

The study demonstrated that TAM density and activation status, as indicated by the predomination of SOCS1 or SOCS3 proteins (respectively M1 or M2) in dogs may suggest that these cells can promote or inhibit neoplasm growth and development of metastatic mammary carcinoma.

Conflict of interest statement.- The authors declare that no competing interests exist.

Acknowledgements.- This study was supported in part by Fundação de Amparo a Pesquisa do Estado da Bahia (FAPESB) and Coordenação de Aperfeiçoamento de Pessoal de Nível Superior (CAPES). The authors thank the Program for Technological Development in Tools for Health-PDTIS-FIOCRUZ-for the use of its facilities. AEL and GDC are grateful for CNPq research fellowship (PQ).

\section{REFERENCES}

Cassali G.D., Lavalle G.E., Ferreira E., Estrela-Lima A., De Nardi A.B., Ghever C., Sobral R.A., Amorim R.L., Oliveira L.O., Sueiro F.A.R., Beserra H.E.O., Bertagnolli A.C., Gamba C.O., Damasceno K.A., Campos C.B., Araújo M.R., Campos L.C., Monteiro L.N., Nunes F.C., Horta R.S., Reis D.C., Tanaka N.M., Grandi F., Ubukata R., Batschinski K., Terra E.M., Salvador R.C.L., Jark P.C., Delecrodi J.E.R., Nascimento N.A., Silva D.N., Silva L.P., Ferreira K.C.R.S., Frehse M.S., Santos G.W., Silva E.O., Guim T.N., Kerr B., Cintra P.P., Silva F.B.F., Leite J.S., Mello M.F.V., Ferreira M.L.G., Fukunasu H., Salgado B.S. \& Torres R. 2014. Consensus for the diagnosis, prognosis and treatment of canine mammary tumors, 2013. Braz. J. Vet. Pathol. 7:38-69.

Elston E.W. \& Ellis I.O. 1993. Method for grading breast cancer. J. Clin. Pathol 46(2):189-190. <http://dx.doi.org/10.1136/jcp.46.2.189-b><PMid:8459046>

Epelman S., Lavine K.J. \& Randolph G.J. 2014. Origin and functions of tissues macrophages. Immunity 41(1):21-35. <http://dx.doi.org/10.1016/j. immuni.2014.06.013><PMid:25035951>

Estrela-Lima A., Araújo M.S., Costa-Neto J.M., Teixeira-Carvalho A., BarrouinMelo S.M., Cardoso S.V., Martins-Filho A.O., Serakides R. \& Cassali G.D. 
2010. Immunophenotypic features of tumor infiltrating lymphocytes from mammary carcinomas in female dogs associated with prognostic factors and survival rates. BMC Cancer 10(1):256. <http://dx.doi.org/10.1186/14712407-10-256><PMid:20525350>

Fairweather D. \& Cihakova D. 2009. Alternatively activated macrophages in infection and autoimmunity. J. Autoimmun. 33(3/4):222-230. <http:// dx.doi.org/10.1016/j.jaut.2009.09.012><PMid:19819674>

Guiet R., Van Goethem E., Cougoule C., Balor S., Valette A., Al Saati T., Lowell C.A., Le Cabec V. \& Maridonneau-Parini I. 2011. The process of macrophage migration promotes matriz metalloproteinase-independent invasion by tumor cells. J. Immunol. 187(7):3806-3814. <http://dx.doi.org/10.4049/ jimmunol.1101245><PMid:21880978>

Heys S.D., Stewart K.N., Mckenzie E.J., Miller I.D., Wong S.Y.C., Sellar G. \& Rees A. 2012. Characterisation of tumour-infiltrating macrophages: impact on response and survival in patients receiving primary chemotherapy for breast cancer. Breast Cancer Res. Treat. 135(2):539-548. <http://dx.doi. org/10.1007/s10549-012-2190-6><PMid:22886449>

Hu B., Shen K.-P., Xu L. \& Deng S. 2012. Inflammation, macrophage in cancer progression and Chinese herbal treatment. J. Basic Clin. Pharm. 3(2):269272. <http://dx.doi.org/10.4103/0976-0105.103820><PMid:24826036>

Italiani P. \& Boraschi D. 2014. From monocytes to M1/M2 macrophages: phenotypical vs. functional differentiation. Front Immunol. 5:514. <http:// dx.doi.org/10.3389/fimmu.2014.00514> <PMid:25368618>

Kim J.H., Hur J.H., Lee S.M., Im K.S., Kim N.H. \& Sur J.H. 2012. Correlation of Foxp3 positive regulatory $\mathrm{T}$ cells with prognostic factors in canine mammary carcinomas. Vet. J. 193(1):222-227. <http://dx.doi.org/10.1016/j. tvjl.2011.10.022><PMid:22130461>

Król M., Pawlowski K.M., Majchrzak K., Gajewska M., Majewska A. \& Motyl T. 2012. Global gene expression profiles of canine macrophages and canine mammary cancer cells grown as a co-culture in vitro. BMC Vet. Res. 8(1):16. <http://dx.doi.org/10.1186/1746-6148-8-16><PMid:22353646>

Lim H.Y., Im K.S., Kim N.H., Kim H.W., Shin J.I., Yhee J.Y. \& Sur J.H. 2015. Effects of obesity and obesity-related molecules on canine mammary gland tumors. Vet. Pathol. 52(6):1045-1051. <http://dx.doi.org/10.1177/0300985815579994> $<$ PMid:25883120>

Luna L.G. 1968. Manual of Histologic Staining Methods of the Armed Forces Institute of Pathology. McGraw-Hill, New York.

Mantovani A. 2007. Inflammation and cancer: the macrophage conection. Medicina 67:32-34. <PMid:17408018>

Mantovani A. 2011. B cells and macrophages in cancer: yin and yang. Nat. Med. 17(3):285-286. <http://dx.doi.org/10.1038/nm0311-285> $<$ PMid:21383737>

Mantovani A. 2014. The immunogeneity of breast cancer revisited. Eur.J. Cancer 50:S100-S101. <http://dx.doi.org/10.1016/S0959-8049(14)70083-8>

Mantovani A., Sozzani S., Locati M., Allavena P. \& Sica A. 2002. Macrophage polarization: tumor-associated macrophages as a paradigm for polarized M2 mononuclear phagocytes. Trends Immunol. 23(11):549-555. <http:// dx.doi.org/10.1016/S1471-4906(02)02302-5> <PMid:12401408>

Mantovani A., Sica A., Sozzani S., Allavena P., Vecchi A. \& Locati M. 2004. The chemokine system in diverse forms of macrophage activation and polarization. Trends Immunol. 25(12):677-686. <http://dx.doi.org/10.1016/j. it.2004.09.015><PMid:15530839>

Martinez F.0., Helming L. \& Gordon S. 2009. Alternative activation of macrophages: an immunologic functional perspective. Ann. Rev. Immunol. 27(1):451483. <http://dx.doi.org/10.1146/annurev.immunol.021908.132532> $<$ PMid:19105661>
Misdorp W., Else W., Hellmen E. \& Lipscomb T.P. 1999. Histological classification of the mammary tumors of the dog and cat. In: Ibid. (Eds), WHO International Histological Classification Tumors of Domestic Animals, Second Series. AFIP, Washington. 59p.

Murray P.J. \& Wynn T.A. 2011. Obstacles and opportunities for understanding macrophage polarization. J. Leukoc. Biol. 89(4):557-563. <http://dx.doi. org/10.1189/jlb.0710409><PMid:21248152>

Murray P.J., Allen J.E., Biswas S.K., Fisher E.A., Gilroy D.W., Goerdt S., Gordon S., Hamilton J.A., Ivashkiv L.B., Lawrence T., Locati M., Mantovani A., Martinez F.O., Mege J.-L., Mosser D.M., Natoli G., Saeij J.P., Schultze J.L., Shirey K.A., Sica A., Suttles J., Udalova I., Van Ginderachter J.A., Vogel S.N. \& Wynn T.A. 2014. Macrophage activation and polarization: nomenclature and experimental guidelines. Immunity 41(1):14-20. <http://dx.doi. org/10.1016/j.immuni.2014.06.008><PMid:25035950>

Ono M. 2008. Review article molecular links between tumor angiogenesis and inflammation: inflammatory stimuli of macrophages and cancer cells as target for therapeutic strategy. Cancer Sci. 9(8):1501-1506. <http:// dx.doi.org/10.1111/j.1349-7006.2008.00853.x><PMid:18754859>

Owen L.N. 1980. TNM Classification of tumors in Domestic Animals. World Health Organization, Geneva, p.26-32.

Pollard J.W. 2008. Macrophages define the invasive microenvironment in breast cancer. J. Leukoc. Biol. 84(3):623-630.<http://dx.doi.org/10.1189/ jlb.1107762><PMid:18467655>

Qian B., Deng Y., Im J.H., Muschel R.J., Zou Y., Li J., Lang R.A. \& Pollard J.W. 2009. A distinct macrophage population mediates metastatic breast cancer cell extravasation, establishment and growth. PLoS One 4(8):e6562.<http:// dx.doi.org/10.1371/journal.pone.0006562><PMid:19668347>

Qin H., Holdbrooks A.T., Liu Y., Reynolds S.L., Yanagisawa L.L. \& Benveniste E.N. 2012. SOCS3 Deficiency promotes M1 macrophage polarization and inflammation. J. Immunol. 189(7):3439-3448. <http://dx.doi.org/10.4049/ jimmunol.1201168 ><PMid:22925925>

Rohan T.E., Xue X., Lin H.M., D’Alfonso T.M., Ginter P.S., Oktay M.H., Robinson B.D., Ginsberg M., Gertler F.B., Glass A.G., Sparano J.A., Condeelis J.S. \& Jones J.G. 2014. Tumor microenvironment of metastasis and risk of distant metastasis of breast cancer. J. Natl Cancer Inst. 106(8). <http://dx.doi. org/10.1093/jnci/dju136><PMid:24895374>

Saeki K., Endo Y., Uchida K., Nishimura R., Sasaki N. \& Nakagawa T. 2012. Significance of tumor-infiltrating immune cells in spontaneous canine mammary gland tumors: 140 cases. J. Vet. Med. Sci. 74(2):227-230. <http:// dx.doi.org/10.1292/jvms.11-0118> <PMid:21937855>

Sica A., Larghi P., Mancino A., Rubino L., Porta C., Totaro M.G., Rimoldi M., Biswas S.K., Allavena P. \& Mantovani A. 2008. Macrophage polarization in tumor progression. Semin. Cancer Biol. 18(5):349-355. <http://dx.doi. org/10.1016/j.semcancer.2008.03.004 > PMid:18467122>

Sindrilaru A., Peters T., Wieschalka S., Baican C., Baican A., Peter H., Hainzl A., Schatz S., Qi Y., Schlecht A., Weiss J.M., Wlaschek M., Sunderkötter C. \& Scharffetter-Kochanek K. 2011. An unrestrained proinflammatory M1 macrophage population induced by iron impairs wound healing in humans and mice. J. Clin. Invest. 121(3):985-997. <http://dx.doi.org/10.1172/ JCI44490> <PMid:21317534>

Starr R. \& Hilton D.J. 1998. SOCS: suppressors of cytokine signaling. Int. J. Biochem. Cell Biol. 30(10):1081-1085. <http://dx.doi.org/10.1016/ S1357-2725(98)00067-3><PMid:9785473>

Toríbio J.M.M.L., Costa-Neto J.M., Bavia M.E., Lima A.E.S., Cardim L.L., Carneiro D.D.M.T., Martins-Filho E.F. \& Ribeiro L.G.R. 2012. Detection of spatial clusters for breast cancer in canines in the city of Salvador, Bahia. Ciência Rural 42:98-104. 